\title{
Argon laser photocoagulation in the dog stomach
}

\author{
S. G. BOWN ${ }^{12}$, P. R. SALMON 1 , D. F. KELLY, B. M. CALDER, H. PEARSON, \\ B. M. Q. WEAVER, AND A. E. READ \\ From the Departments of Medicine, Pathology and Veterinary Surgery, University of Bristol, Bristol
}

SUMMARY Laser photocoagulation is one of a number of methods currently under investigation for the endoscopic treatment of gastrointestinal haemorrhage. The Argon ion and Neodymium Yttrium Aluminium Garnet (Nd YAG) lasers are theoretically suitable as the beam from each may be transmitted via a flexible fibre. Argon laser photocoagulation has been shown to be effective and we have elucidated which factors determine its safety and efficacy. Studies on normal canine gastric mucosa showed that the depth of tissue damage depended chiefly on the total incident laser energy on any one spot, and that below $50 \mathrm{~J}$ the risk of perforation was extremely low. The energy density was much less important. The haemostatic effect depended more on the laser power. In artificial bleeding gastric ulcers in heparinised dogs the most effective level was 7-9 W, at which 22 out of 23 ulcers $(96 \%)$ stopped bleeding completely, compared with one out of 12 controls. Photocoagulation was achieved in these cases with energies well within the safe limits. The procedure was effective endoscopically, and these results justify early clinical studies in man.

Emergency endoscopy has now become a routine procedure in many hospitals to identify the source of bleeding in patients presenting with upper gastrointestinal haemorrhage. However, until recently endoscopy was limited to diagnosis. Many such haemorrhages stop spontaneously before endoscopy can be carried out but, for those that do not, the advantages of therapeutic endoscopy for the control of haemorrhage are considerable. If haemostasis can be induced during endoscopy blood transfusion requirements may be considerably reduced, emergency surgery can be avoided, and elective surgery, if necessary at all, can be carried out at a convenient time on a stable patient.

Methods that have been tried include local injections (Johnston and Rogers, 1973; Soehendra and Werner, 1976), electrocoagulation (Gaisford, 1975; Papp, 1976; Piercey et al., 1978), the heater probe (Protell et al., 1977b), tissue glues (Matsumoto, 1967; Protell et al., 1977a), and lasers (Silverstein et al., 1976, 1977, 1978; Kiefhaber et al., 1977; Fruhmorgen et al., 1975, 1976). An excellent review is given by Katon (1976). Good results have been

'Present address: University College Hospital, London W.C.1.

${ }^{2}$ Address for correspondence: Dr S. G. Bown, The Rayne Institute, University College Hospital Medical School, 5 University Street, London W.C.1.

Received for publication 12 February 1979 reported by some groups, but, as yet, no method has received widespread recognition.

Laser is an acronym for Light Amplification by the Stimulated Emission of Radiation, but in simple terms a laser is a high power source of light, which can be sharply focused to give an extremely high power density over a very small area which can be exactly defined. The energy is absorbed in living tissue as heat and the effect is that of localised, intense thermal changes. The energy can be easily and exactly controlled, and, as there is no electrical or mechanical contact with the bleeding site, the nature and extent of the effect on the underlying tissue may be accurately predicted, in sharp contrast with the situation with electrocoagulation. Laser photocoagulation is therefore a very promising method, but its safety and efficacy have not yet been fully established.

Two types of laser are currently available of sufficient power for photocoagulation in the gastrointestinal tract, and the beam of which can be transmitted via a flexible fibre. These are the Argon ion laser, which is a gas laser producing a visible light beam in the blue-green region of the spectrum, and the Nd YAG (Neodymium Yttrium Aluminium Garnet) laser, which is a solid state laser emitting a beam in the near infra-red region of the spectrum. Both lasers are effective, but the different wavelengths of the emitted beams produce different 
absorption patterns in living tissue. In this paper we have evaluated the safety and efficacy of the Argon ion laser in inducing haemostasis in experimental gastric lesions in dogs as a prelude to its endoscopic use in man.

\section{Methods}

We used a Spectra-Physics 171 Argon ion laser which produces a continuous wave beam of up to $15 \mathrm{~W}$. The experimental arrangement is shown diagramatically in Fig. 1. The laser beam is focused on to the end of a 200 micron single quartz fibre, $4 \mathrm{~m}$ in length, and held in a micrometer on the end of the laser. The free end of the fibre is passed down a $3 \mathrm{~m}$ catheter of $2 \mathrm{~mm}$ outside diameter through a connecting box which enables carbon dioxide gas to be blown down the catheter coaxially with the laser fibre (Silverstein et al., 1978). The tip of the fibre is adjusted to be about $2 \mathrm{~mm}$ inside the distal end of the catheter, and the catheter and fibre together can be passed down the biopsy channel of a standard endoscope. The coaxial carbon dioxide stream is used in two ways-a slow continuous background flow serves to keep the tip of the fibre clean and to prevent any blood or secretions being sucked back into the catheter. A much faster flow rate initiated by a foot switch is used to blow blood away from a bleeding site before laser photocoagulation. The gas flow rates may be pre-set independently. The fibre is aimed using a low power beam (about $0.1 \%$

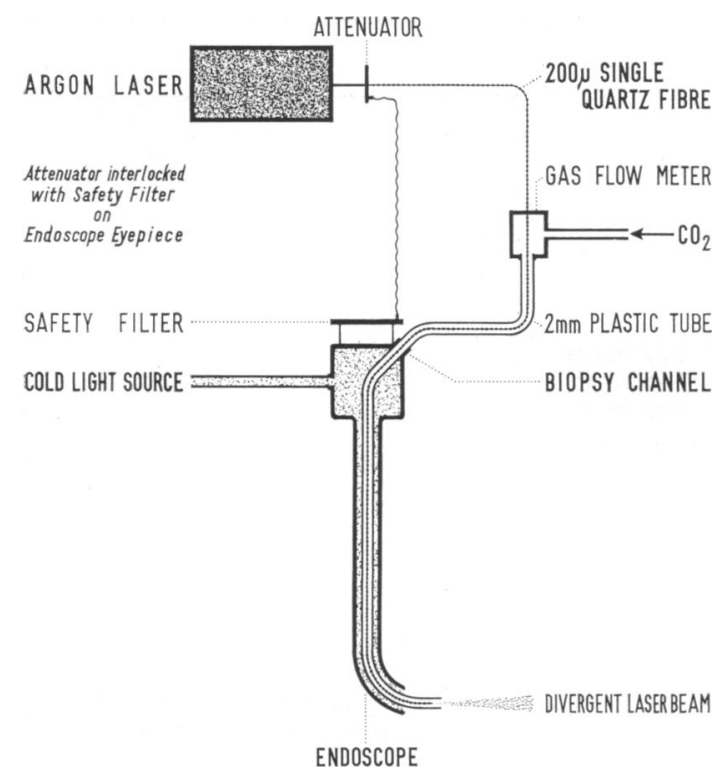

Fig. 1 Endoscopic photocoagulation: experimental arrangement of laser. of the peak power) initially. The foot switch moves an attenuator out of the beam when full power is required. The power is adjusted by varying the laser current, and measured at the fibre tip before use, on a separate meter. Careful safety precautions are essential and were taken under the supervision of the University Safety Officer.

Under general anaesthesia studies were carried out at laparotomy and endoscopically on eight beagles (weight $8-13 \mathrm{~kg}$ ). The major risk of laser photocoagulation is that the beam will perforate the wall of the organ being treated, and to assess this risk we carried out experiments to create laser lesions on normal canine gastric mucosa. We studied the effect of varying the exposure time (from one to 10 seconds), and the laser power (from $2 \mathrm{~W}$ to $12 \mathrm{~W}$ ). The beam spot size on tissues varies with the distance from the fibre tip to the target tissue as the beam diverges with a full angle of 12 degrees and we used this to study different values of power density (power/unit area) by varying this distance between 2 and $20 \mathrm{~mm}$. Lesions were examined histologically in the acute phase and at one week in order to assess the nature and extent of laser-induced tissue damage.

Histological sections were made through the centre of each lesion and stained with haematoxylin and eosin. These were examined under a microscope with a graticule eyepiece and the maximum depth of microscopic damage was measured. This was expressed as a percentage of the thickness of the layer in which the deepest damage was seen (mucosa, submucosa, or muscularis propria). Lesions extending to the serosa were regarded as full thickness.

The second phase of the study was to assess the haemostatic effect of the laser and, to do this, experimental gastric ulcers were made with the Quinton ulcer maker (Protell el al., 1976). This produces ulcers of a standard depth, so enabling the extent of any further damage produced by laser treatment to be readily assessed. These experiments were performed in heparinised animals and the heparin administration was monitored by whole blood clotting times to produce a clotting time at least three times that of controls. Ulcers were made at gastrotomy or by passing the ulcer-maker perorally and monitoring the site of the artificial lesions endoscopically. Alternatively, ulcers were made by a 'lift and cut' technique in which a fold of mucosa was lifted and cut across its base. Ulcers produced in this way bled more profusely, although their depth could not be accurately predicted. The blood loss was quantified by collection in wide mouthed vials from the edge of each ulcer for one minute after it was made. At least one standard ulcer in each animal was left untreated as a control, and the blood loss measured again in the second and third minutes. 
Each ulcer was treated for up to one minute, although care was taken not to exceed the critical energy on any one spot in the ulcer (see below). For those in which complete haemostasis was not obtained, blood was collected again during the third minute.

\section{Results}

NORMAL MUCOSA

Results were analysed by comparing the total laser energy ( $=$ power $\times$ time) and the energy densitythat is, the energy per unit area of mucosa, which depends on the total energy and the distance between the fibre tip and mucosa-with the depth of histological damage for each lesion.

The results are shown in Figs. 2 and 3 for lesions

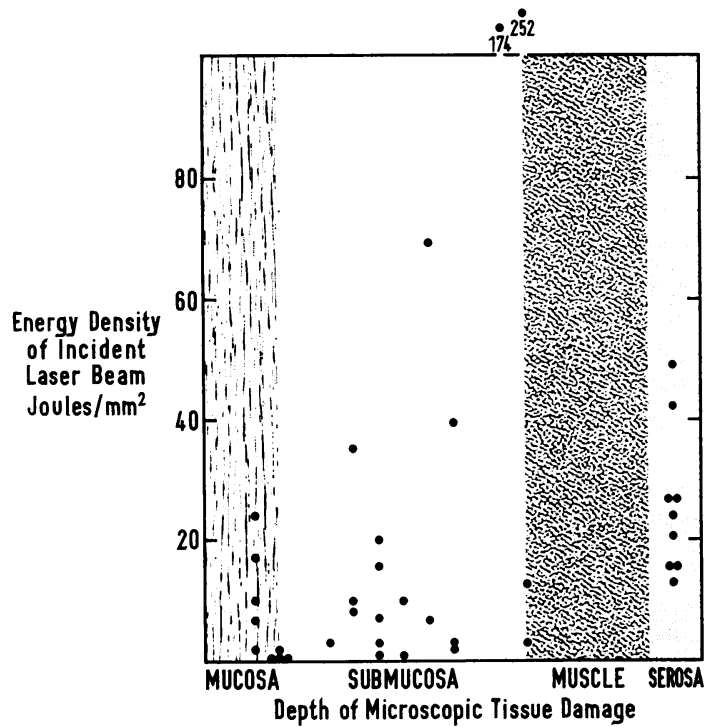

Fig. 2 Normal gastric mucosa. Effect of energy density on depth of histological damage in acute lesions.

studied acutely, and 4 and 5 for those studied at one week.

Figure 2 shows that there is a general tendency for the depth of damage to increase with the energy density. However, there are marked anomalies, as many lesions show full thickness damage or even perforation at low values of energy density, whereas, in others, high energy densities cause no damage below the submucosa. In contrast Fig. 3 shows how the damage varied with the total incident laser energy. In this case the correlation is much closer and indeed there is a critical value of energy at about $50 \mathrm{~J}$. All lesions receiving more total energy than this show full thickness damage or perforation, whereas, at lower energies, there is no damage below the submucosa. However, this is only true with incident

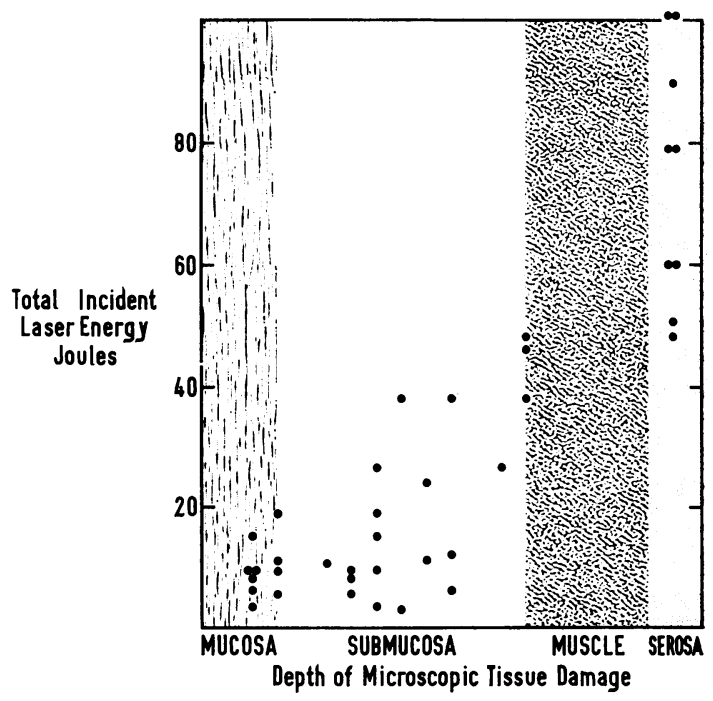

Fig. 3 Normal gastric mucosa. Effect of total energy on depth of histological damage in acute lesions.

powers of $4 \mathrm{~W}$ and above. At $3 \mathrm{~W}$, we were unable to produce full thickness damage, even using an exposure of 33 seconds, which gave an energy of $100 \mathrm{~J}$-twice the critical level.

Figures 4 and 5 show similar measurements taken on lesions studied at one week. The same patterns are apparent in each graph as in the lesions studied acutely, and the critical energy is at a similar level. For comparison, Fig. 6 shows the variation of the depth of damage with the power applied for the

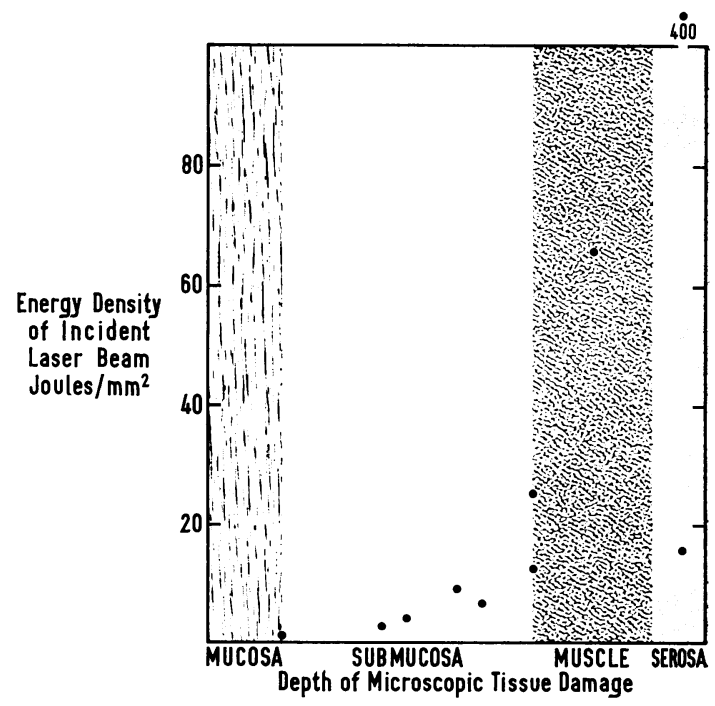

Fig. 4 Normal gastric mucosa. Effect of energy density on depth of histological damage at one week. 


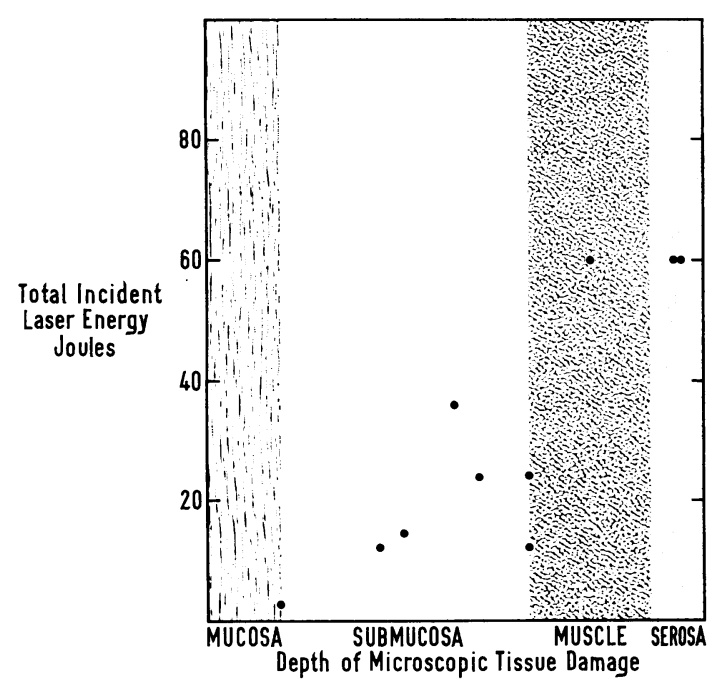

Fig. 5 Normal gastric mucosa. Effect of total energy on depth of histological damage at one week.

same lesions as those shown in Figs. 2 and 3. This illustrates the wide variation in damage that can occur at one power setting. For example, at $7.5 \mathrm{~W}$, the damage varied from $70 \%$ of the mucosa (with an exposure of one second) to perforation (with an exposure of 10 seconds). In contrast, the range of damage seen at any one energy level is significantly less. (Fig. 3).

\section{EXPERIMENTAL BLEEDING ULCERS} Assessment of rate of bleeding

Four out of the five ulcers in unheparinised animals stopped bleeding in less than three minutes with an average blood loss of $1.6 \mathrm{ml}$ in three minutes.

The blood loss from ulcers in heparinised animals is shown in Table 1. Standard ulcers were made with the Quinton ulcer maker and non-standard ulcers by the 'lift and cut' method. Eleven out of 12 untreated control ulcers continued to bleed for more than three minutes. Table 1 shows that there is no significant difference between the blood loss in the first minute from standard control ulcers and from standard treated ulcers, although there is greater
Table 1 Blood loss from artificial gastric ulcers in heparinised dogs

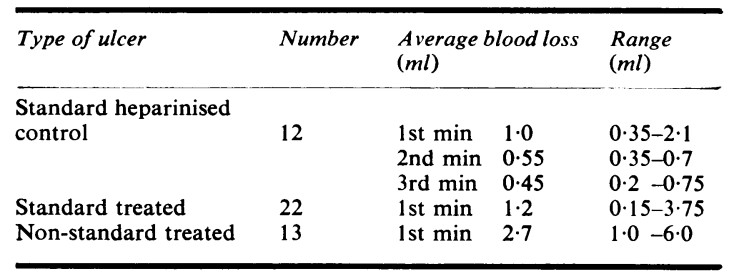

blood loss from the non-standard ulcers. Thus we have a suitable model for testing the photocoagulation effect of the laser.

\section{Effect of laser photocoagulation}

The results are shown in Table 2. The laser was tested in three power ranges: 2-5 W, 7-9 W, and at $12 \mathrm{~W}$. At $7-9 \mathrm{~W}, 22$ out of 23 ulcers $(96 \%)$ stopped bleeding, significantly more than those treated at $2-5 \mathrm{~W}(\mathrm{P}<0.001), 12 \mathrm{~W}(\mathrm{P}<0.001)$, or untreated controls $(\mathrm{P}<0.001)$. More ulcers treated at $2-5 \mathrm{~W}$ and $12 \mathrm{~W}$ stopped bleeding than controls, but the numbers are too small to reach statistical significance. Only standard ulcers were treated with $2-5 \mathrm{~W}$, but at the higher powers the non-standard ulcers provided a greater test, as haemostasis was

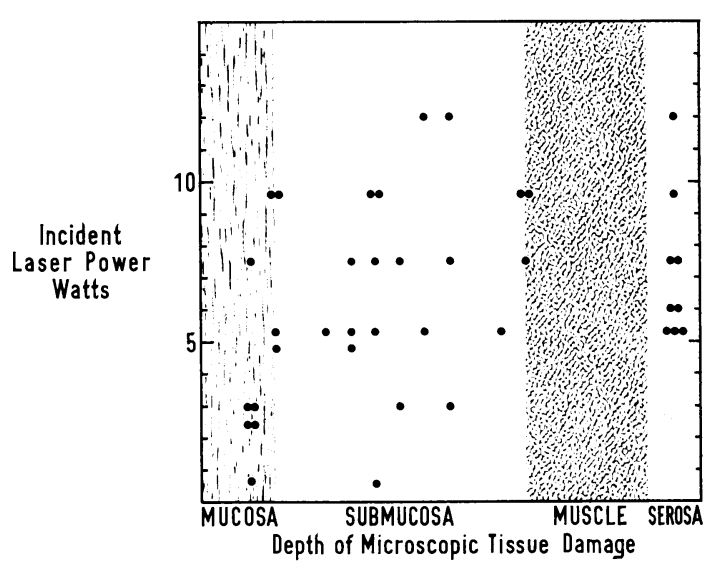

Fig. 6 Normal gastric mucosa. Effect of incident power on depth of histological damage in acute lesions.

Table 2 Haemostatic effect of photocoagulation

\begin{tabular}{|c|c|c|c|c|c|c|c|c|}
\hline \multirow{2}{*}{$\begin{array}{l}\text { Power } \\
(W)\end{array}$} & \multicolumn{2}{|c|}{ Standard ulcers } & \multicolumn{2}{|c|}{ Non-standard ulcers } & \multicolumn{2}{|c|}{ Total } & \multirow{2}{*}{$\begin{array}{l}\text { Difference from } \\
\text { control }\end{array}$} & \multirow{2}{*}{$\begin{array}{l}\text { Average blood loss } \\
\text { in } 3 r d \min (\mathrm{ml})\end{array}$} \\
\hline & No. & Haemostasis & No. & Haemostasis & No. & $\begin{array}{l}\text { Haemostasis } \\
\text { (no.) (\%) }\end{array}$ & & \\
\hline $\begin{array}{l}2-5 \\
7-9 \\
12\end{array}$ & $\begin{array}{r}6 \\
14 \\
2\end{array}$ & $\begin{array}{r}2 \\
14 \\
2\end{array}$ & $\begin{array}{l}- \\
9 \\
3\end{array}$ & $\begin{array}{l}- \\
-\end{array}$ & $\begin{array}{r}6 \\
23 \\
5\end{array}$ & $\begin{array}{rr}2 & 33 \\
22 & 96 \\
2 & 40\end{array}$ & $\begin{array}{l}\text { NS } \\
P<0.001 \\
\text { NS }\end{array}$ & $\begin{array}{c}0.1 \\
<0.05 \\
<0.05\end{array}$ \\
\hline
\end{tabular}

NS: not significant. 
achieved only at powers in the 7-9 W range. However, ulcers treated at all powers showed a marked reduction in the bleeding rate in the third minute, and only two of the eight ulcers that did not stop bleeding completely after treatment bled sufficiently for it to be possible to collect the blood. These were both treated with 2-5 W. The remaining six showed a slight ooze, and we estimated that the blood loss from each of these was less than $0.05 \mathrm{ml}$.

All lesions were examined histologically. Untreated standard ulcers showed a loss of tissue ranging from $10 \%$ to $90 \%$ of the submucosa. In treated standard ulcers, the maximum depth of damage seen was $30 \%$ of the muscularis propria. Detailed histological description of the tissue changes will be given at a later date.

\section{Discussion}

Lasers have been used for some years for photocoagulation in the eye (Landers et al., 1976; Diabetic Retinopathy Study Research Group 1976) but have only recently been considered for photocoagulation in other organs. The first report of endoscopic laser photocoagulation was by Goodale et al. (1970), who succeeded in stopping bleeding from artificial erosions in the canine stomach using a carbon dioxide laser and a rigid endoscope. However, only the Argon and Nd YAG laser beams can be transmitted via flexible fibres. Good photocoagulation effects have been reported for both (Silverstein et al., 1977; Kiefhaber et al., 1977) and these are discussed further below, but little work has been published on which factors are most important in determining the extent of tissue damage produced. Fruhmorgen et al. (1975) have made chronic studies on the argon laser treatment of normal oesophagus, stomach, duodenum, and colon of dogs without causing perforation in spite of using energies of up to $90 \mathrm{~J}$. However, their maximum laser power was only $2 \mathrm{~W}$ and we have shown that at $3 \mathrm{~W}$ it is not possible to cause full thickness damage even at twice the critical energy. Our studies on normal mucosa have included powers up to $12 \mathrm{~W}$, so covering the range 6-9 W currently thought to be the most effective for photocoagulation by ourselves and Silverstein et al. (1977).

To explain our experimental conclusion that the total energy is the most important factor in determining tissue damage, it is necessary to consider the nature of the interactions between the laser light and the tissue. When a laser beam is incident on living tissue, four possible physical effects may occur. These are reflection, transmission, absorption, and scattering. The reflected light is a hazard for the operator and goggles or a protective filter on the eyepiece of the endoscope are essential, but it does not affect the tissue. Of the light entering the tissue, a certain amount is absorbed (depending on the absorption coefficient, and on the thickness of the tissue) and the rest is transmitted. All the observed histological effects are caused by the light energy that is absorbed; these effects may be seen exactly where the light falls, or the light may be scattered in any direction, and absorbed in the neighbouring areas. In this situation, the overall effect on one small area within the tissue depends on both the light falling on surrounding areas and the light falling on the area itself. In addition, energy absorbed as heat in one area may be conducted thermally to adjacent areas. These effects are shown in Fig. 7.

If all the energy were absorbed in the exact area on which it fell, without scattering or heat conduction, the depth of tissue damage would depend solely on the energy density of the incident beam and not its total energy. Our results show clearly that this is not the case and that there must be some lateral spread of the energy within the tissue as the total energy is the more important factor. This is fortunate from the endoscopic point of view and indicates that the fibre-mucosa distance (which is difficult to estimate endoscopically) is not critical in determining the risk of full thickness damage. This is brought out in Fig. 8 in which the variation of depth of histological damage with total energy is shown for a few selected values of energy density. All these lines cross, illustrating that whatever the value of energy density (within the range of values studied) it is still

\section{INCIDENT BEAM OF LASER LIGHT}
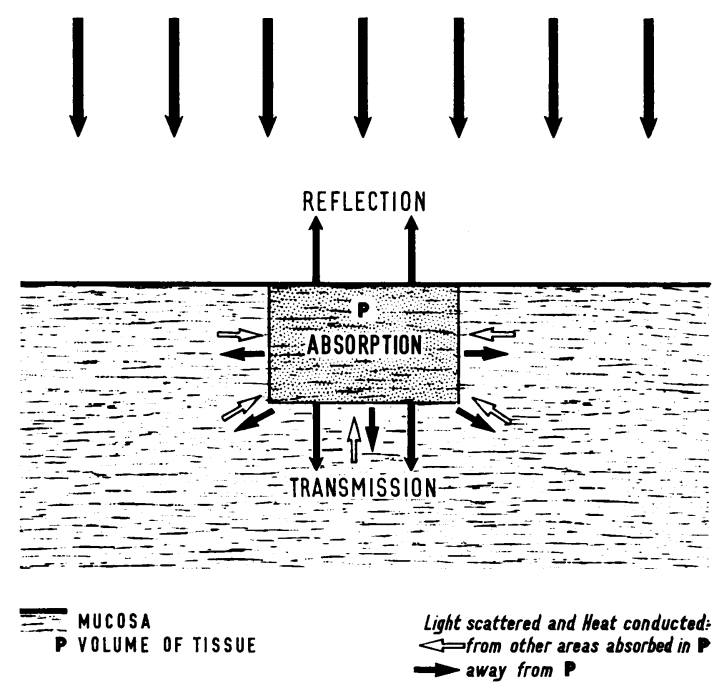

Fig. 7 Effect of laser light on a small volume of tissue at the surface of an area of mucosa. 


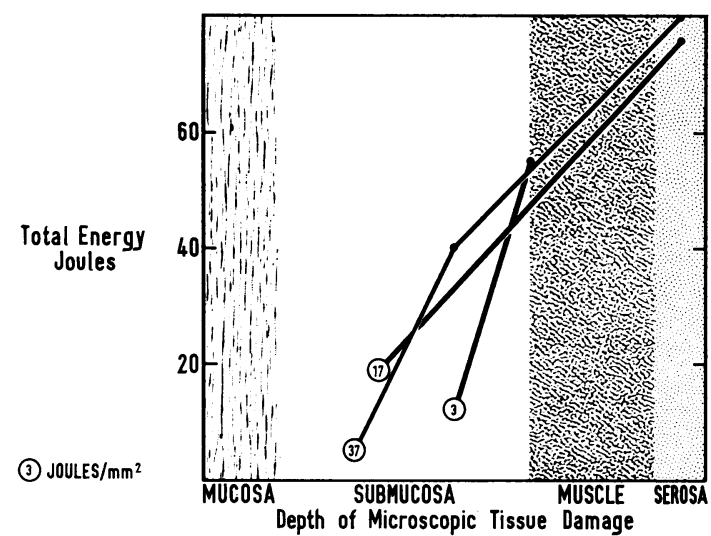

Fig. 8 Normal gastric mucosa. Effect of total energy on depth of histological damage at three different values of energy density.

the total energy that is the more important factor in determining the depth of effect. However, the fibremucosa distance (which determines the energy density for a particular total incident energy) does have an effect (Fig. 2) and this may be clearly illustrated by plotting this distance against the depths of damage for a few selected values of the total incident energy (Fig. 9). The line for $50 \mathrm{~J}$ is at the critical value for total energy, and in this special case only (within the range of values studied) it is the fibre-mucosa distance that determines whether or not full thickness damage occurs.

Experiments on normal gastric mucosa in the dog may not closely simulate many clinical situations, but the concept of a critical energy, beyond which perforation is likely as shown above,

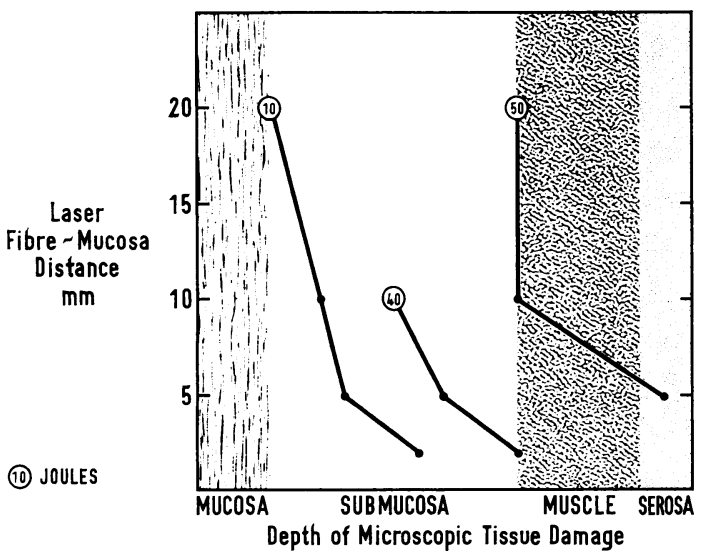

Fig. 9 Normal gastric mucosa. Effect of fibre-mucosa distance on depth of histological damage at three different values of total energy. is extremely important. In due course, it should be possible to determine approximate values for this energy in other organs (oesophagus, duodenum, and colon) and in different parts of the human gastrointestinal tract. It will be more difficult to predict the safe energy limits for deep, penetrating lesions such as chronic ulcers, but these lesions are usually surrounded by considerable fibrous tissue that is likely to absorb more energy safely than normal mucosa.

Our studies on an animal model of bleeding gastric ulcers show that effective haemostasis can be obtained with a laser power of 7-9 W, whereas at lower (2-5 W) and higher powers (12 W) photocoagulation is much less effective. These results are entirely consistent with those of Silverstein et al. (1977) who showed that photocoagulation at $6.5 \mathrm{~W}$ was effective, whereas at $1 \mathrm{~W}$ it was not. We cannot confirm the results of Dwyer et al. (1975) and Waitman et al. (1975) who both reported haemostasis in experimental bleeding lesions in the canine stomach with powers of less than $1 \mathrm{~W}$. However, the bleeding rates of the lesions used by both these groups were probably low compared with those used by Silverstein and ourselves, as they did not use anticoagulants. We have observed partial haemostasis at $2 \mathrm{~W}$, particularly in slowly oozing lesions, so a difference in the severity of bleeding may account for the apparent discrepancy in the results. In ulcers treated at open gastrotomy, the fibre-tip-to-mucosa distance was kept constant and we studied the photocoagulation effects at distances of $5 \mathrm{~mm}$ and $10 \mathrm{~mm}$. In the 7-9 W group, eight ulcers were treated at $5 \mathrm{~mm}$ and 12 at $10 \mathrm{~mm}$. In two lesions, it was not possible to achieve haemostasis at $5 \mathrm{~mm}$, but by increasing the distance to $10 \mathrm{~mm}$ haemostasis was achieved. The one lesion in this group that did not stop bleeding was only treated at $10 \mathrm{~mm}$. The numbers are small but these results suggest that photocoagulation may be more effective at $10 \mathrm{~mm}$, when the power density is $180-240 \mathrm{~W} / \mathrm{cm}^{2}$. Nevertheless, it is still effective up to $950 \mathrm{~W} / \mathrm{cm}^{2}(9 \mathrm{~W}$ at $5 \mathrm{~mm}$ with our fibre which gives a full angle divergence of $12^{\circ}$ ). Once again, these results are fully compatible with those of Silverstein et al. (1977) who showed that the optimum power density for photocoagulation at $6.5 \mathrm{~W}$ incident power was $160-487 \mathrm{~W} / \mathrm{cm}^{2}$. We did not carry out any coagulations at distances greater than $10 \mathrm{~mm}$, as we found that our maximum acceptable flow rate of $\mathrm{CO}_{2}$. $(50 \mathrm{ml} / \mathrm{s})$ was ineffective at greater distances.

It has become apparent that laser-induced haemostasis is more dependent on the power of the laser, whereas the risk of perforation depends more on the total energy applied. In the latter case, the effect of the duration of exposure is almost as im- 
portant as the power level, and the product of the two, the energy, is the best parameter to consider when assessing the risk of perforation. It is encouraging to find that, with our treated standard ulcers, by keeping the energy incident on any one bleeding point in an ulcer below the critical energy, no cases of full thickness damage were seen. Brunetaud et al. (1978b) put a similar limit on their exposure time for individual bleeding points $(5 \mathrm{~s}$ at $6.5 \mathrm{~W}=32.5 \mathrm{~J}$ ) and by so doing have also avoided producing any perforations.

The lesions created by the ulcer maker cannot be compared directly with any clinical situation, although they represent a reasonable model for acute gastric and duodenal ulcers, as these are usually shallow with little scarring. However, this is an extremely important group as, if haemorrhage from these lesions can be stopped endoscopically, complete resolution is likely to be possible without surgery. Nevertheless, this model has proved most valuable in elucidating which parameters determine the safety and effectiveness of laser photocoagulation.

Argon laser photocoagulation has been used clinically in France (Brunetaud et al., 1978a) and Germany (Fruhmorgen et al., 1976) with good results. However, a number of questions still remain unanswered. For example, is there a risk of increased bleeding from large blood vessels-for example, varices-with laser photocoagulation? Are there undesirable long-term effects? Our initial studies indicate that the Argon ion laser causes quantitatively predictable effects in the normal canine stomach. As a result, the factors determining the risk of perforation have been established. Argon laser photocoagulation is effective in producing haemostasis in experimental bleeding gastric ulcers in heparinised animals with applied energies well within our established safe limits. In our animal model, this procedure appears to be safe and effective, suggesting its early selective application in pilot clinical studies.

We should like to thank Professor G. H. Arthur and the staff of the School of Veterinary Science, Langford, for their help and advice throughout this project. We should also like to thank Professor J. Peacock for his support and Professor H. Hopkins as advisor to the project. This work was carried out with the support of a grant from the DHSS.

\section{References}

Brunetaud, J. M., Enger, A., Flament, J. B., Petit, J., Berjot, M., and Moschetto, Y. (1978b). Utilisation d'un laser à argon ionisé en endoscopie digestive; photocoagulation des lesions hemorragiques. (To be published.)
Brunetaud, J. M., Enger, A., Maffioli, C., Seys, G. A., Potron, G., and Berjot, M. (1978a). L'hémostase perendoscopique par le laser des hémorragies digestives, d'origine haute: premiers résultats. La Nouvelle Presse Medicale, 7, 1486.

Dwyer, R. M., Haverback, B. J., Bass, M., and Cherlow, J. (1975). Laser-induced hemostasis in the canine stomach. Use of a flexible fiberoptic delivery system. Journal of the American Medical Association, 231, 486-489.

Frühmorgen, P., Bodem, F., Reidenbach, H. D., Kaduk, B., and Demling, L. (1976). Endoscopic laser coagulation of bleeding gastrointestinal lesions with report of the first therapeutic application in man. Gastrointestinal Endoscopy, 23, 73-75.

Frühmorgen, P., Kaduk, B., Reidenbach, H. D., Bodem, F., Demling, L., and Brand, H. (1975). Long-term observations in endoscopic laser coagulations in the gastrointestinal tract. Endoscopy, 7, 189-196.

Gaisford, W. D. (1975). Endoscopic control of active upper gastrointestinal bleeding. (Abstract). Clinical Congress, American College of Surgeons, San Francisco, October, 1975.

Goodale, R. L., Okada, A., Gonazales, R., Borner, J. W., Edlich, R. F., and Wangensteen, O. H. (1970). Rapid endoscopic control of bleeding gastric erosions by laser radiation. Archives of Surgery, 101, 211-214.

Johnston, G. W., and Rogers, H. W. (1973). A review of 15 years' experience in the use of sclerotherapy in the control of acute haemorrhage from oesophageal varices. British Journal of Surgery, 60, 797-800.

Katon, R. M. (1976). Experimental control of gastrointestinal haemorrhage via the endoscope: a new era dawns. Gastroenterology, 70, 272-277.

Kiefhaber, P., Nath, G., and Moritz, K. (1977). Endoscopical control of massive gastrointestinal haemorrhage by irradiation with a high-power Neodymium-YAG laser. Progress in Surgery, 15, 140-155.

Landers, M. B., Wolbarsht, M. L., and Shaw, H. E., Jr. (1976). The current status of laser usage in ophthalmology. Annals of the New York Academy of Sciences, 267, 230-246.

Matsumoto, T., Hardaway, R. M., Heisterkamp, C. A., Pani, K. C., and Leonard, F. (1967). Higher homologous cyanoacrylate tissue adhesives in surgery of internal organs. Archives of Surgery, 94, 861-864.

Papp, J. P. (1976). Endoscopic electrocoagulation of upper gastrointestinal haemorrhage. Journal of the American Medical Association, 236, 2076-2079.

Diabetic Retinopathy Study Research Group (1976). Preliminary report on effects of photocoagulation therapy. American Journal of Ophthalmology, 81, 383-396.

Piercey, J. R. A., Auth D. C. Silverstein, F. E., Willard, H. R., Dennis, M. B., Ellefson, D. M., Davis, D. M., Protell, R. L., and Rubin, C. E. (1978) Electrosurgical treatment of experimental bleeding canine gastric ulcers. Gastroenterology, 74, 527-534.

Protell, R. L. Auth. D. C., Terou, F., and Rubin, C. E. (1977b). A miniaturised endoscopic heater probe; tests of efficacy in experimental acute gastric ulcer bleeding. (Abstract). Gastrointestinal Endoscopy, 23, 238.

Protell, R. L., Silverstein, F. E., Gulacsik, C., Martin, T. R., and Dennis, M. B. (1977a). Cyanoacrylate glue (Flucrylate) fails to stop bleeding from experimental gastric ulcers. (Abstract). Gastroenterology, 72, 1114.

Protell, R. L., Silverstein, F. E., Piercey, J. R. A., Dennis, M. B., Sprake, W., and Rubin, C. E. (1976). A reproducible animal model of acute bleeding ulcer - the 'ulcer maker'. Gastroenterology, 71, 961-964.

Silverstein, F. E. Auth. D. C., Rubin, C. E., and Protell, R. L. (1976). High power argon laser treatment via standard endoscopes. 1. A preliminary study of efficacy in control 
of experimental erosive bleeding. Gastroenterology, 71, 558-563.

Silverstein, F. E., Protell, R. L., Gulacsik, C., Auth, D. C., Deltenre, M., Dennis, M. B., Piercey, J. R. A., Rubin, C. E. (1978). Endoscopic laser treatment. 3. Development and testing of a gas-jet-assisted argon laser waveguide in control of bleeding experimental ulcers. Gastroenterology, 74, 232239.

Silverstein, F. E., Protell, R. L., Piercey, J. R. A., Rubin, C. E. Auth. D. C., and Dennis, M. B. (1977). Endoscopic laser treatment. 2. Comparison of the efficacy of high and low power photocoagulation in control of severely bleeding experimental ulcers in dogs. Gastroenterology, 73, 481-486.

Soehendra, N., and Werner, B. (1976). New technique for endoscopic treatment of bleeding Gastric ulcer. Endoscopy, 8, 85-87.

Waitman, A. M., Spira, I., and Chryssanthou, C. P. (1975). Fibreoptic-coupled argon laser in the control of experimentally produced gastric bleeding. Gastrointestinal Endoscopy, 22, 78-81.

\section{The June 1979 Issue}

\section{THE JUNE 1979 ISSUE CONTAINS THE FOLLOWING PAPERS}

\section{Sir Arthur Hurst THOMAS HUNT}

Morphology of experimental antibiotic-associated enterocolitis in the hamster: a model for human pseudomembranous colitis and antibiotic-associated diarrhoea A. B. PRICE, H. E. LARSON, AND JULIE CROW

Colonic myoelectrical activity in man: comparison of recording techniques and methods of analysis C. J. STODDARD, H. L. DUTHIE, R. H. SMALLWOOD, AND D. A. LINKENS

Method of preparing isolated colonic epithelial cells (colonocytes) for metabolic studies W. E. W. ROEDIGER AND S. C. TRUELOVE

Cyclic AMP and cyclic GMP levels in human colonic mucosa before and during chenodeoxycholic acid therapy G. R. CORAZZA, R. CICCARELLI, F. CACIAGLI, AND G. GASBARRINI

High flow oxygen therapy for pneumatosis coli S. HOLT, H. M. GILMOUR, T. A. S. BUIST, K. MARWICK, AND R. C. HEADING

Absorption studies in patients six to 10 years after construction of ileostomy reservoirs L. O. NILSSON, H. ANDERSSON, L. HULTÉN, R. JAGENBURG, N. G. KOCK, H. E. MYRVOLD, AND B. PHILIPSON

Ultrastructural analysis of plasma cells in coeliac patients M. GUIX, J. M. SKINNER, AND R. WHITEHEAD
Small intestinal intraepithelial lymphocyte levels in cow's milk protein intolerance A. D. PHILLIPS, S. J. RICE, N. E. FRANCE, AND J. A. WALKER-SMITH

Effect of 16, 16-dimethyl prostaglandin $E_{2}$ on the gastric mucosal barrier J. P. BOLTON AND M. M. COHEN

Lipid composition of bile in diabetics and obesitymatched controls G. B. HABER AND K. W. HEATON

HLA and cell-mediated immunity in $\mathrm{HB}_{\mathrm{s}} \mathrm{AG}$ negative chronic active hepatitis A. J. M. VOGTEN, R. G. SHORTER, AND G. OPELZ

\section{Clinical trial}

Controlled trial of maintenance cimetidine treatment in healed duodenal ulcer: short and long-term effects M. S. DRONFIELD, A. J. BATCHELOR, W. LARKWORTHY, AND M. J. S. LANGMAN

\section{Case report}

Idiopathic portal hypertension (perisinusoidal fibrosis) after renal transplantation C. NATAF, G. FELDMANN, D. LEBREC, G. DEGOTT, J.-M. DESCAMPS, B. RUEFF, AND J.-P. BENHAMOU

\section{Progress report}

Antacids and peptic ulcer-a reappraisal T. MORRIS AND J. RHODES

Notes and activities; Books

Copies are still available and may be obtained from the PUBLISHING MANAGER, BRITISH MEDICAL ASSOCIATION, TAVISTOCK SQUARE, LONDON WC1H 9JR, price $£ 3.50$, including postage 